\title{
Midbrain hemorrhage mimicking pituitary apoplexy in patient using anticoagulation therapy
}

\author{
Leonardo M. Batista', Daniel M. Prevedello², Paul Gardner², \\ Ricardo L. Carrau 2,3, Carl H. Snyderman²,3, Amin B. Kassam4
}

Pituitary apoplexy represents a hemorrhage or infarction of the pituitary gland and has its occurrence often related in the context of a pituitary adenoma ${ }^{1}$. In classical pituitary apoplexy, headache, usually of sudden and severe onset, is the most common presenting symptom and hypertension and anticoagulation have been described as relevant predisposing factors ${ }^{1,2}$. The risk of cranial nerve palsies leading to double vision and/or vision loss and the risk of acute panhypopituitarysm leading to death in the event of apoplexy have to be seriously considered. Thus a quick diagnosis confirmation is imperative to avoid delays on the management.

We present a patient who had the typical clinical and history course associated with pituitary apoplexy but in whom, based on imaging examination for confirmation immediately before surgery, a precise midbrain hemorrhage was diagnosed. The known pituitary adenoma was unchanged and the surgery was cancelled. The present case adds a new perspective in which other site than the sella may be causing the pituitary apoplexy-mimicking symptoms in patients chronically treated with anticoagulants.

\section{CASE}

This study was approved by the local Institutional Review Board (IRB), and a waiver of informed consent was provided. A 76-year-old white man presented with sudden onset of headache while sitting on the commode. This was accompanied by feeling of numbness in his head and inability to open either eye. He also felt weakness and numbness on the left side of his face and was rushed into an outside emergency department.

He had a past medical history significant for previous partially resection of a pituitary adenoma and was also positive for non-valvular atrial fibrillation, for which he was on chronic use of Warfarin.

Due to the evident diagnosis of pituitary apoplexy leading to bilateral third nerve palsy, the patient was transferred from a smaller facility to UPMC Presbyterian Emergency Department without any imaging study in order to possibly undergo endoscopic endonasal decompression of the sella and cavernous sinuses emergently.

\section{Examination}

At the admission he was somnolent but easily arousable and oriented to self and place. Pupils were unequal: right pupil was $2 \mathrm{~mm}$ and the left was $3 \mathrm{~mm}$, both sluggishly reactive to light. He had a disconjugate primary gaze. Complete left third cranial nerve palsy was identified so he could not open the left eye due to the severe eyelid ptosis. When passively opened, his left eye was completely abducted. He could not cross the midline when asked to look to the right. On the right eye, partial third cranial nerve palsy was evident.
Correspondence

Department of Neurological

Surgery University of Pittsburgh

School of Medicine

200 Lothrop Street, Suite B400

Pittsburgh, PA, 15206, USA

E-mail: dprevedello@gmail.com

Received 26 July 2009

Received in final form 15 September 2009

Accepted 28 September 2009
HEMORRAGIA MESENCEFÁLICA MIMETIZANDO APOPLEXIA PITUIÁRIA EM PACIENTE COM TERAPIA ANTICOAGULANTE

${ }^{1} J$. Philip Kistler Stroke Research Center, Department of Neurology, Massachusetts General Hospital. Boston, MA, USA; ${ }^{2}$ Department of Neurological Surgery, University of Pittsburgh, School of Medicine. Pittsburgh, PA, USA; ' ${ }^{2}$ Department of Otolaryngology, University of Pittsburgh, School of Medicine. Pittsburgh, PA, USA; ${ }^{4}$ Chan Soon-Shiong Neuroscience Institute, John Wayne Cancer Institute at Saint John's Health Center, Santa Monica, CA, USA. 

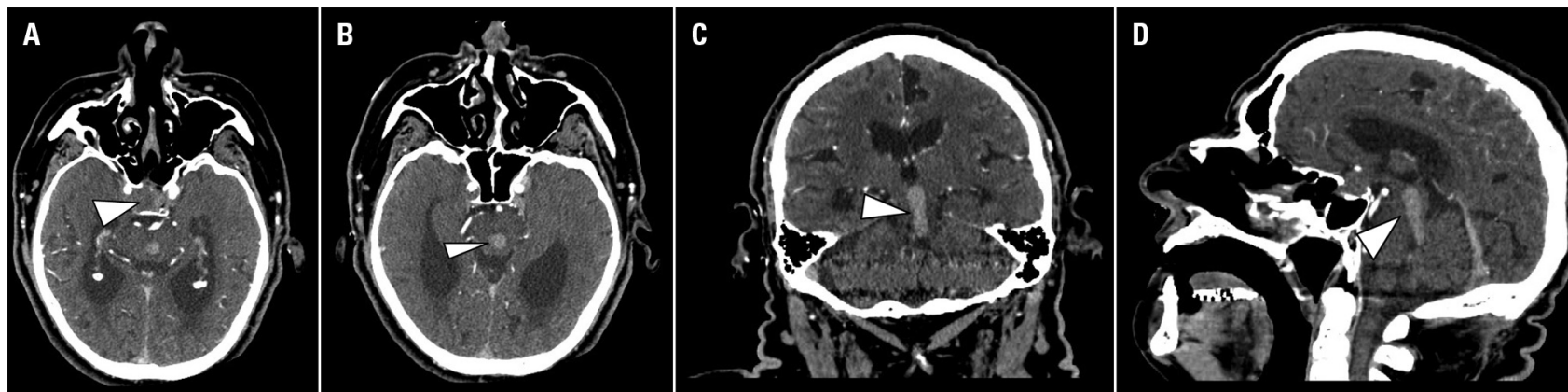

Figure. Contrast CT-scan. Pituitary adenoma [A] is visualized (white arrow). There is evidence of a previous transsphenoidal resection. Axial view $[B]$ of the midbrain hemorrhage (white arrow). Hydrocephalus ex vacuo evidenced by dilatation of the lateral ventricle. Coronal [C] and Sagittal [D] views of hemorrhage in the midbrain and pons reaching the fourth ventricle (white arrows).

He could partially open the right eye and perform down gaze. He was totally unable to perform upgaze or medial gaze. The six cranial nerve function was preserved on both sides. INR on presentation was 2.0 , white count was 12.0 with normal differential count, hemoglobin 16.3 and creatinine 1.3 .

\section{Course}

The skull base team at UPMC was ready to perform a prompt expanded endonasal approach for decompression of sella and cavernous sinuses. The operating room was ready to receive the patient. Since he had a pacemaker and couldn't be submitted to a MRI, a CT on admission, performed to elucidate the magnitude of the supposedly hemorrhagic sellar tumor, showed a discrete pituitary adenoma without signs of degeneration (Figure A). However, there was a hyperdense coalescent lesion in the dorsal paramedian midbrain and pons (Figure $B$ and $C$ ) that extended to the fourth ventricle (Figure D). On his way to the operating room, the pathway was changed and the patient was transferred to the ICU. On a follow-up head non-contrast $\mathrm{CT}$ scan, this lesion looked to be consistent with acute blood in the midbrain, with extension to the fourth ventricle. There was hydrocephalus ex vacuo but no signs of subacute or acute hydrocephalus.

\section{DISCUSSION}

A pituitary apoplexy was first suspected due to the context of a pituitary adenoma and to the clinical presentation. In Wakai's series, from 560 cases of pituitary adenoma operated, $16.6 \%$ had a confirmed hemorrhage from the tumor (pituitary apoplexy) and $6.8 \%$ presented the apoplexy manifested by major neurological alterations such as decrease of the consciousness status, vision loss and ocular palsies ${ }^{3}$. These evidences show that the incidence of this complication is relatively high and its potential to cause serious neurological injury in patients with a pituitary adenoma is a reality. A retrospective analyses of 45 patients with classical pituitary apoplexy suggested that cases with no evidence of neuro-ophthalmic signs achieve good outcomes with conservative management ${ }^{4}$. Our patient, on the other hand, presented severe third nerve palsy in the acute stage, which reinforced the urgency for a prompt surgical approach ${ }^{2}$. The characteristic manifestations of visual disturbance and ophthalmoplegia usually suggest a parasellar lesion causing optic nerve/ chiasm and cavernous sinuses compression, which contributed to the suppose diagnosis of pituitary apoplexy in this case. In retrospect, the lack of VI nerve palsies was unusual for a devastating presentation of pituitary apoplexy that was already affecting both third nerves. However, isolated III nerve palsies have been reported ${ }^{5,6}$. Independently, the explanation was evident once the hemorrhagic lesion was detected in the mesencephalum sparing the abducens nuclea.

Anticoagulation is well known as an important precipitating factor of hemorrhage and although warfarin decreases the risk of stroke in patients with nonvalvular atrial fibrillation, it increases the risk of major bleeding ${ }^{7}$. Supratherapeutic INR levels $(>3.0)$ has been reported to double the incidence of intracerebral hemorrhage (ICH) compared with the therapeutic range (2.0 to 3.0) presented by the presented patient ${ }^{8}$.

The absolute rate of spontaneous ICH is $\geq 1 \%$ per year in stroke-prone patients ${ }^{9}$, and the well-known predictors for increased early deaths in these patients include the clinical and radiological severity of bleeding as well as being on a Warfarin regimen at the onset of stroke ${ }^{10}$. Despite the serious clinical and neurological presentation of the patient, he was rapidly diagnosed and well-managed, which increased his rehabilitation chances.

It is known that admission and pre-operative imaging are routinely performed in all suspected cases of pituitary apoplexy which would avoid a mismanagement of any sort, however the aim of the present report was to illustrate that patients chronically treated with anticoagulants have potentially increased risk of bleeding which can lead to apoplexy-like symptoms. This is particularly 
important in patients with a positive previous history of pituitary adenoma.

In summary, pituitary apoplexy is a life-threatening condition and non-sellar lesions may rarely mimic its clinical symptoms during a chronic treatment with anticoagulants, mostly in the presence of a positive history for pituitary adenoma. Therefore is imperative that this differential diagnosis be ruled out quickly in order to avoid delays on the management.

\section{REFERENCES}

1. Tan TM, Caputo C, Mehta A, Hatfield EC, Martin NM, Meeran K. Pituitary macroadenomas: are combination antiplatelet and anticoagulant therapy contraindicated? A case report. J Med Case Reports 2007;1:74.

2. Chang CV, Felicio AC, Toscanini AC, Teixeira MJ, Cunha-Neto MBC. Pituitary tumor apoplexy. Arq Neuropsiquiatr 2009;67:328-333.
3. Wakai S, Fukushima T, Teramoto A, Sano K. Pituitary apoplexy: its incidence and clinical significance. J Neurosurg 1981;55:187-193.

4. Sibal L, Ball SG, Connolly V, et al. Pituitary apoplexy: a review of clinical presentation, management and outcome in 45 cases. Pituitary 2004;7:157-163.

5. Miranda M, Barros L, Knopfelmacher M, et al. Apoplexia pituitaria seguida de remissao endocrina: relato de dois casos. Arq Neuropsiquiatr 1998; 56:449-452.

6. Kim SH, Lee KC, Kim SH. Cranial nerve palsies accompanying pituitary tumour. J Clin Neurosci 2007;14:1158-1162.

7. EAFT (European Atrial Fibrillation Trial) study group. Secondary prevention in non-rheumatic atrial fibrillation after transient ischemic attack or minor stroke. Lancet 1993;342:1255-1262.

8. Walker AM, Bennett D. Epidemiology and outcomes in patients with atrial fibrillation in the United States. Heart Rhythm 2008;5:1365-1372.

9. Hart RG. What causes intracerebral hemorrhage during warfarin therapy? Neurology 2000;55:907-908.

10. Tetri S, Mantymaki L, Juvela S, et al. Impact of ischemic heart disease and atrial fibrillation on survival after spontaneous intracerebral hemorrhage. J Neurosurg 2008;108:1172-1177. 